\title{
Revisión sistemática de las concepciones de cultura organizacional
}

\author{
Systematic review of the conceptions of organizational culture
}

Wilson Redin Gonzáles-Limas* orcid.org/0000-0002-8089-9057

Claudia Fernanda Bastidas-Jurado' orcid.org/0000-0002-4131-0174

Hernán Alberto Figueroa-Chaves' orcid.org/0000-0002-4087-5667

Christian Alexander Zambrano-Guerrero² orcid.org/0000-0001-8482-0345

Sonia Maritza Matabanchoy-Tulcán² orcid.org/0000-0002-3681-8440

1 Programa de Psicología, Universidad de Nariño. Pasto, Colombia.

2 Grupo de Investigación CONEPSI, Programa de Psicología, Universidad de Nariño. Pasto, Colombia

Fecha de recepción: Septiembre 12 - $2017 \quad$ Fecha de revisión: Diciembre 12 - $2017 \quad$ Fecha de aceptación: Abril 13 - 2018

Gonzáles-Limas WR, Bastidas-Jurado CF, Figueroa-Chaves HA, Zambrano-Guerrero CA, Matabanchoy-Tulcán SM. Revisión sistemática de las concepciones de cultura organizacional. Univ. Salud. 2018;20(2):200-214. DOI: http://dx.doi.org/10.22267/rus.182002.123

\begin{abstract}
Resumen
Introducción: Las diferentes concepciones de la cultura organizacional se han desarrollado en las últimas décadas, dependiendo de éstas, se proponen, desarrollan y evalúan estrategias de intervención encaminadas a mejorar el bienestar de los miembros que las conforman. Objetivo: Describir las concepciones de cultura organizacional en las publicaciones de la base de datos EBSCO host durante los últimos seis años. Materiales y métodos: Revisión sistemática descriptiva de 71 artículos publicados en la base de datos EBSCO host, desde el año 2012 hasta el 2017. Resultados: Se identificó 110 definiciones de cultura organizacional, las cuales se clasificaron en cinco subcategorías: valores y creencias organizacionales, actitud organizacional, identidad organizacional, empresarial y aprendizaje organizacional. Conclusiones: La cultura organizacional se comprende desde diversas concepciones, vislumbrando con ello el desarrollo y aporte académico que ha tenido dicha temática.
\end{abstract}

Palabras clave: Cultura organizacional; revisión sistemática; valores; creencias. (Fuente: DeCS, Bireme).

\begin{abstract}
Introduction: The different conceptions of organizational culture have been developed in recent decades. Depending on these, intervention strategies are proposed, developed and evaluated with the aim of improving the well-being of the members that make them up. Objective: To describe the conceptions of organizational culture in the publications of the EBSCO host database over the last six years. Materials and methods: A descriptive systematic review of 71 articles published in the database EBSCO host from 2012 to 2017 was made. Results: 110 definitions of organizational culture were identified, which were classified into five subcategories: organizational values and beliefs, organizational attitude, organizational identity, business and organizational learning. Conclusions: The organizational culture is understood from different conceptions, thus envisioning the development and academic contribution that this thematic has had.
\end{abstract}

Keywords: Organizational culture; systematic review; values; beliefs. (Source: DeCS, Bireme).

*Autor de correspondencia Wilson Redin Gonzáles Limas e-mail: wilsongonzalez@udenar.edu.co 


\section{Introducción}

Algunos autores refieren que la gestión del talento humano se desarrolla en el marco de la cultura organizacional(1), en ese sentido la concepción del ser humano en una organización y su participación en ella implica el reconocimiento de competencias, conocimientos $\mathrm{y}$ habilidades que tiene el trabajador $\mathrm{y}$ el establecimiento de políticas, normas procesos y procedimientos que dan un marco de referencia para el desarrollo de las funciones, reflejándose en la productividad de la organización.

Estudios refieren que en las organizaciones donde la cultura organizacional se interesa por las personas se presenta un mayor bienestar laboral en sus trabajadores(2). De esta manera, la cultura organizacional impacta positivamente en el comportamiento organizacional y por ende en la salud y bienestar del trabajador.

En el desarrollo conceptual de la cultura organizacional, se encuentran diversas concepciones entendidas como un conjunto de aprendizajes adquiridos que permiten a la persona construir o comprender una idea(3); así, se identifica un desarrollo en la concepción de la cultura organizacional que en sus inicios se aborda desde la antropología y la sociología, llegando a la actualidad a entenderse como una parte del ambiente organizacional interno y externo(4). Se ha dado un estudio amplio de la cultura organizacional, encontrando similitudes y diferencias entre concepciones, múltiples comprensiones, interpretaciones y formas de medirla a través del tiempo ${ }^{(5)}$.

El estudio de la cultura organizacional es de gran importancia debido a que aporta al conocimiento científico, gracias a su diversidad y complejidad está condicionado por la relación de factores internos y externos que legitiman su carácter particular de expresión y los procesos que la dinamizan(6). Así mismo, le permite diseñar planes y estrategias que generan cambios y desarrollo duradero a partir de la identidad que se ha formado dentro de la organización(7), propiciando compromisos colectivos y estabilidad social, la creación de un sentido de misión, dirección y un alto nivel de adaptabilidad y flexibilidad( ${ }^{(8)}$.

A partir de la necesidad de las organizaciones de conocer e identificar su cultura organizacional para hacer frente a las necesidades del contextos, se encuentran diferentes formas de evaluarla a partir de la utilización de métodos cuantitativos y cualitativos, es así que se evidencian metodologías como la aplicación de instrumentos, entrevistas, grupos focales y revisión documental(9), que forman parte del proceso de exploración y análisis del comportamiento de un grupo de sujetos y permite medir, describir, diagnosticar y/o intervenir, a través de un proceso de toma de decisiones(10).

Para fortalecer la fundamentación conceptual y metodológica de este tema se revisó las diferentes concepciones de cultura organizacional en las publicaciones de la base de datos EBSCO host durante los últimos seis años.

\section{Materiales y métodos}

Se realizó una metodología de revisión sistemática descriptiva de literatura, entendida como una investigación observacional y retrospectiva, focalizada en la metodología, los hallazgos y las conclusiones de cada estudio(11), que permite condensar los resultados de múltiples investigaciones, obteniéndose la descripción a manera de síntesis de la información encontrada, con el fin de dar respuesta a una pregunta específica(12). Se realizaron los siguientes pasos:

1) Formulación de la pregunta y objetivo de investigación;

2) Especificación de los criterios de inclusión y exclusión de los artículos;

3) Formulación del plan de búsqueda de literatura;

4) Búsqueda de artículos en la base de datos EBSCO host;

5) Evaluación de la calidad de los estudios de acuerdo a criterios establecidos;

6) Sistematización de la información;

7) Interpretación y presentación de resultados. 
Para la selección de los diferentes estudios se tuvo en cuenta los siguientes criterios de inclusión:

1) Artículos publicados en la base de datos EBSCO host entre los años 2012 y 2017;

2) Publicación en idioma español, portugués e inglés;

3) Artículos que contengan en el título la frase "cultura organizacional" para los idiomas español y portugués y "organizational culture" para las publicaciones de idioma inglés;

4) Artículo de investigación finalizada;

5) Acceso al texto completo. Los criterios de exclusión fueron: artículos que no contaban con definiciones de cultura organizacional, metodología o resultados y shortpapers.

Se recurrió a la base EBSCO host que cuenta con 14 bases de datos en diversas áreas del conocimiento, contiene texto completo, índice y resúmenes.

Se seleccionaron de los documentos que cumplieran los criterios de inclusión, se depuro y organizó la información recolectada a través de una matriz de datos, para su posterior análisis univariado, se estableció frecuencias mediante la herramienta de los programas Excel 2013 y el Paquete Estadístico SPSS versión 24.0.

\section{Resultados}

Se encontraron 71 artículos que cumplieron con los criterios de inclusión, se observó que en el año 2014 hubo el mayor número de publicaciones (30\%), seguido de 2015 (24\%); 2013 y 2016 (15\%); 2012 (13\%) y 2017 (3\%).

Los estudios sobre el tema se realizaron en 41 países, de los cuales 13,04\% se llevaron a cabo en India; 8,7\% en Estados Unidos de América; 5,43\% en Brasil y Turquía (cada uno); 4,35\% en Grecia, Colombia y España (cada uno); 3,26\% en Alemania, Israel, México y Paquistán (cada uno);
2,17\% en Australia, Francia, Japón, China, Holanda y Malasia (cada uno); y 1,09\% en Tailandia, Austria, Dinamarca, Finlandia, Hungría, Irlanda, Italia, Países Bajos, Filipinas, Rusia, Eslovenia, Sudáfrica, Suecia, Suiza, Taiwán, Reino Unido, Chipre, Croacia, Cuba, Egipto, Emiratos Árabes, Unión Europea, Irán, Estambul, Malta y Polonia (cada uno).

El 78,87\% de artículos se encuentran publicados en idioma inglés, $14,08 \%$ en español y $7,04 \%$ en portugués. En ellos se identificó 110 definiciones de cultura organizacional que se presentan en las siguientes subcategorías:

\section{Valores y creencias organizacionales}

En esta subcategoría se encontró que el 9,5\% de los artículos retoman la definición de cultura organizacional del autor Schein de 1985 (Tabla 1).

\section{Actitud organizacional}

El 33,3\% de los artículos retoman la definición de cultura organizacional del autor Pettigrew de 1979 (Tabla 2).

\section{Identidad organizacional}

El 12,5\% de los artículos retoman la definición de cultura organizacional de los autores Cameron y Quinn de 1999 (Tabla 3).

\section{Subcategoría empresarial y aprendizaje organizacional}

En la subcategoría empresarial los artículos retoman definiciones de cultura organizacional de los autores Douglas de 1982, Shrivastava de 1983, Weick de 1985, Kotter y Heskett de 1992, Black de 2003, Schein de 2004, Ooi y Arumugam de 2006, Jenkins et al., de 2008, Ahiybor de 2014, Ghanavati de 2014. Mientras que en la subcategoría aprendizaje organizacional el 26,7\% de los artículos retoman la definición de cultura organizacional del autor Schein de 1985 (Tabla 4). 
Tabla 1. Definiciones de cultura organizacional de acuerdo a la subcategoría Valores y creencias organizacionales

\begin{tabular}{|c|c|c|}
\hline Subcategoría Valores y creencias & $\mathbf{F i}^{*}$ & $\%$ \\
\hline $\begin{array}{l}\text { Es un todo complejo que incluye conocimiento, creencias, arte, moral, ley, costumbre y cualquier capacidad o } \\
\text { hábito adquirido por un individuo como miembro de la sociedad [Tylor, 1971] }]^{(13)} \text {. }\end{array}$ & 1 & 2,4 \\
\hline Como un conjunto de creencias, normas y valores que tienen influencia sobre la conducta [Evan, 1976](13). & 1 & 2,4 \\
\hline $\begin{array}{l}\text { Es el patrón de creencias y expectativas compartidas por los miembros que producen normas que configuran } \\
\text { el comportamiento [Swartz y Jordan, 1980](14). }\end{array}$ & 1 & 2,4 \\
\hline $\begin{array}{l}\text { Es la codificación colectiva de mentes o valores, creencias y pensamientos que distinguen a los miembros entre } \\
\text { sí [Hofsted, 1980] }{ }^{(14,15) .}\end{array}$ & 2 & 4,8 \\
\hline Conjunto de creencias, de símbolos, de lemas, y de ritos en la empresa [Deal y Kennedy, 1982](13,16). & 2 & 4,8 \\
\hline Como los valores compartidos de todos los grupos, incluyendo los sociales y los mayores [Uttal, 1983](14). & 1 & 2,4 \\
\hline $\begin{array}{l}\text { Es un sistema de representaciones y de valores compartidos por todos los miembros de la empresa [Lemaitre, } \\
1984]^{(13)} \text {. }\end{array}$ & 1 & 2,4 \\
\hline $\begin{array}{l}\text { Es un sistema que reúne los aspectos expresivos y afectivos en un sistema colectivo de significados simbólicos: } \\
\text { los mitos, las ideologías y los valores [Allaire y Firsirotu, 1984] }]^{(13) .}\end{array}$ & 1 & 2,4 \\
\hline $\begin{array}{l}\text { Como creencias, valores y normas que determinan cómo se hacen las cosas y definen los estándares esperados } \\
\text { de conducta de cada individuo [Ulrich, 1984; Deal y Kennedy, 1992](17). }\end{array}$ & 1 & 2,4 \\
\hline $\begin{array}{l}\text { Como un conjunto de valores, creencias y suposiciones que son compartidos por los miembros de una } \\
\text { organización [Schein, 1985](13-18). }\end{array}$ & 4 & 9,5 \\
\hline $\begin{array}{l}\text { Como aquella conformada por varias categorías de creencias tales como la relación organización-entorno, } \\
\text { creencias del carácter de la realidad, verdad, decisiones, naturaleza de la actividad humana y concepción de } \\
\text { relaciones humanas [Jaeger, 1987](13). }\end{array}$ & 1 & 2,4 \\
\hline $\begin{array}{l}\text { Es el patrón de valores y creencias que ayudan a las personas a entender el funcionamiento de la organización } \\
\text { y proporcionan las normas para el comportamiento [Deshpandé y Webster, 1989] }{ }^{(19,20) .}\end{array}$ & 2 & 4,8 \\
\hline $\begin{array}{l}\text { Representa una escala de valores, es decir, un conjunto de factores que definen la filosofía de vida y el estilo } \\
\text { específico de una empresa [Schein 1990](21,22). }\end{array}$ & 2 & 4,8 \\
\hline $\begin{array}{l}\text { Como un conjunto de creencias colectivas, normas, comportamientos, expectativas de grupos, individuos y } \\
\text { equipos en los que interactúan entre sí en la sociedad [Jones y George, 2003; Hargreaves, 1992](14). }\end{array}$ & 1 & 2,4 \\
\hline $\begin{array}{l}\text { Conjunto de creencias, normas, lenguaje, acciones, suposiciones, conocimientos, morales, hábitos y valores } \\
\text { [Ayisi, 1992] }]^{(14) .}\end{array}$ & 1 & 2,4 \\
\hline $\begin{array}{l}\text { Sirve como estructura de intercambio en la cual personas de diferentes orígenes comparten sus valores, } \\
\text { normas e información colectivamente [Faerman, 1994; Varner 1996; Holloway, 2004](14). }\end{array}$ & 1 & 2,4 \\
\hline $\begin{array}{l}\text { Conjunto de valores y presupuestos básicos expresados en elementos simbólicos, que ordenan y atribuyen } \\
\text { significaciones [Fleury y Fischer, 1996](23). }\end{array}$ & 1 & 2,4 \\
\hline Sistema de creencias y valores formados por los empleados [Morgan, 1998](24). & 1 & 2,4 \\
\hline $\begin{array}{l}\text { Las suposiciones, creencias y valores compartidos en la medida en que una organización apoya y valora la } \\
\text { integración del trabajo de los empleados y la vida familiar [Thompson et al., 1999](25). }\end{array}$ & 1 & 2,4 \\
\hline $\begin{array}{l}\text { Conjunto de normas, creencias y valores compartidos por la organización [Cameron y Quinn, 1999; Detert, } \\
\text { Schroeder y Mauriel, 2000; Stock et al., 2007; Yu, 2007] }{ }^{(24,26) .}\end{array}$ & 2 & 4,8 \\
\hline
\end{tabular}


Un conjunto de valores, creencias, presupuestos, percepciones, normas, patrones de comportamiento,

presentes en los objetivos, en las estrategias y en la operacionalización de la empresa [Santos, 2000](23).

Patrones transmitidos de valores, ideas y otros sistemas simbólicos que dan forma al comportamiento de una organización [Sullivan y Wood, 2001] ${ }^{(14) .}$

Es aquello que la gerencia debe identificar; es decir, los valores, las normas de la organización así como los empleados [Wiesner, 2002] ${ }^{(14)}$.

\section{1}

Actúa como pegamento que sostiene a la organización a través de valores compartidos y patrones de pensamientos [Cloke y Goldsmith, 2002] ${ }^{(14)}$.

Patrón de desarrollo reflejado en los sistemas sociales de conocimiento, ideología, valores, leyes y rituales cotidianos [Morgan, 2002](27).

Es el pegamento social que une a la empresa [Lau et al., 2002](28).

Aspecto crítico de las empresas ya que representa un sistema de valores compartidos y creencias operativas [Svyantek y Bott, 2004] ${ }^{(28)}$.

Conjunto de supuestos básicos; normas, valores y tradiciones [Taylor, 2004] ${ }^{(14) .}$

Es la tradicional y acostumbrada hacer cosas en las cuales la gente comparte sus valores, normas, costumbres, tradiciones e incidentes [Bud, 2005] ${ }^{(14) .}$

Desde una perspectiva antropológico-funcionalista, se percibe como instrumento requerido para la satisfacción de necesidades y valores [Sánchez, Holgado, Mora \& Ayuso, 2006](13).

Comprende valores subyacentes, suposiciones y expectativas no escritas [Schur et al., 2009](29).

Se refiere a una parte del ambiente organizacional interno y externo, que es en realidad una combinación de compromisos, creencias y valores comunes [Kiakajouri et al., 2010](4).

Se define como los valores compartidos, las creencias o las percepciones de los empleados dentro de una organización [Robbins y Coulter, 2011] (30).

Es un sistema de valores y creencias compartidas por los miembros que diferencian a la organización de otras organizaciones [Dhingra y Punia, 2016](31).

* Frecuencia de citación de definiciones de la subcategoría valores y creencias organizacionales

Tabla 2. Definiciones de acuerdo a la subcategoría Actitud organizacional

\begin{tabular}{|c|c|c|}
\hline Subcategoría Actitud Organizacional & $\mathbf{F i}^{*}$ & $\%$ \\
\hline $\begin{array}{l}\text { Es un conjunto unido de formas de pensar, de sentir y de actuar más o menos formalizadas que son aprendidas } \\
\text { y compartidas [Rocher, 1968](13). }\end{array}$ & 1 & 16,7 \\
\hline $\begin{array}{l}\text { Se basan en sistemas cognitivos que ayudan a explicar cómo los empleados piensan y toman una decisión } \\
\text { [Pettigrew, 1979](16,32). }\end{array}$ & 2 & 33,3 \\
\hline $\begin{array}{l}\text { Como un sistema colectivo de significado que es seguido por miembros que diferencian su organización de los } \\
\text { demás [Robbins, 1994](33). }\end{array}$ & 1 & 16,7 \\
\hline $\begin{array}{l}\text { La cultura de los institutos debería organizarse de tal manera que ayudaría a los empleados a tomar la decisión } \\
\text { sobre la base de sus pensamientos cognitivos [Thomas y Tung, 2003](14). }\end{array}$ & 1 & 16,7 \\
\hline $\begin{array}{l}\text { Se refiere a un sistema de valores, creencias y comportamiento entre los empleados [Deshpande et al., 1989, } \\
\text { Ravasi y Schultz, 2006] }{ }^{(34)} \text {. }\end{array}$ & 1 & 16,7 \\
\hline
\end{tabular}

\footnotetext{
* Frecuencia de citación de definiciones de la subcategoría actitud organizacional
} 
Tabla 3. Definiciones de acuerdo a la subcategoría Identidad organizacional

\begin{tabular}{|c|c|c|}
\hline Subcategoría Identidad & Fi* $^{*}$ & $\%$ \\
\hline $\begin{array}{l}\text { Es la colección de varias características que representan la organización y la distinguen de otras [Forehand y } \\
\text { Gilmer, 1964](14,32). }\end{array}$ & 2 & 5 \\
\hline $\begin{array}{l}\text { Representa un tema unificador, pero escondido que da una dirección y una movilización en el ámbito de los } \\
\text { recursos [Davis, 1984](13). }\end{array}$ & 1 & 2,5 \\
\hline $\begin{array}{l}\text { Consiste en las suposiciones y creencias subyacentes que los miembros de una organización comparten y } \\
\text { operan inconscientemente [Schein, 1990](22). }\end{array}$ & 1 & 2,5 \\
\hline $\begin{array}{l}\text { Se refiere a un sistema de significados compartidos y manifestaciones del comportamiento organizacional } \\
\text { [Kopelman, 1990](35). }\end{array}$ & 1 & 2,5 \\
\hline Conjunto de creencias y comportamientos, históricamente determinados [Hofstede et al., 1990] ${ }^{(36) .}$ & 1 & 2,5 \\
\hline $\begin{array}{l}\text { Conjunto complejo y multidisciplinario de casi todo aquello que constituye la vida en común en los grupos } \\
\text { sociales [Aktouf, 1990](13). }\end{array}$ & 1 & 2,5 \\
\hline $\begin{array}{l}\text { Sistema de significado compartido donde los miembros de una misma cultura tienen una manera común de ver } \\
\text { eventos y objetos [Kanungo y Jaeger 1990](37). }\end{array}$ & 1 & 2,5 \\
\hline $\begin{array}{l}\text { Es un conjunto de valores, supuestos, interpretaciones y enfoques que caracterizan a las organizaciones y a sus } \\
\text { miembros [Quinn y Spreitzer, 1991] } 20,29,38,39) .\end{array}$ & 4 & 10 \\
\hline Es una compleja construcción desarrollada a lo largo del tiempo [Gordon y Di Tomaso, 1992](40). & 1 & 2,5 \\
\hline $\begin{array}{l}\text { Son actitudes, percepciones, competencias y comportamientos que determinan el compromiso y la seguridad } \\
\text { organizacional [Health and Safety Commission, 1993](41). }\end{array}$ & 1 & 2,5 \\
\hline $\begin{array}{l}\text { Una cultura transaccional se centra en términos de relaciones contractuales explícitas e implícitas. Al igual que } \\
\text { la cultura transaccional, surge una cultura de transformación como consecuencia del comportamiento de } \\
\text { liderazgo transformacional [Bass y Avolio, 1993] }{ }^{(42)} \text {. }\end{array}$ & 1 & 2,5 \\
\hline $\begin{array}{l}\text { Valores, entendimientos, creencias y expectativas que sustentan y refuerzan sus comportamientos y los } \\
\text { distinguen de otros equipos [Schein, 1995] }{ }^{(43) .}\end{array}$ & 1 & 2,5 \\
\hline $\begin{array}{l}\text { Es el estilo de vida compartido acumulativo, cristalizado y cuasi estable de las personas, que se refleja en los } \\
\text { comportamientos de los individuos [Pareek y Rao, 1999] }{ }^{(18) .}\end{array}$ & 1 & 2,5 \\
\hline $\begin{array}{l}\text { En la cultura organizacional se pueden encontrar cuatro tipologías diferentes que explican la estructura cultural } \\
\text { que son; clan, burocrática, adhocracia y mercado [Cameron y Quinn, 1999] } \text { [(24,26,44,45,46). }^{\text {[ }}\end{array}$ & 5 & 12,5 \\
\hline Es la forma en que las cosas son hechas aquí [Shortell, Zazzali, Burns,Alexander, Gillies, Budetti, et al., 2001] ${ }^{(47) .}$ & 1 & 2,5 \\
\hline $\begin{array}{l}\text { Es considerada en su contexto global mediante la comprensión de los esquemas de significación subyacentes en } \\
\text { las interacciones de los individuos en la organización [Zapata, 2002](13). }\end{array}$ & 1 & 2,5 \\
\hline Es una variable organizacional que moldea la identidad de la empresa [Zapata, 2002] ${ }^{(13) .}$ & 1 & 2,5 \\
\hline $\begin{array}{l}\text { Puede ser definida como los valores, creencias y suposiciones ocultas que los miembros de una organización } \\
\text { tienen en común [Miron, Erez y Naveh, 2004](45). }\end{array}$ & 1 & 2,5 \\
\hline $\begin{array}{l}\text { Como una imagen de la filosofía, historia, liderazgo, valores y creencias compartidas de una organización } \\
\text { [Drake, Gulman y Roberts, 2005] }{ }^{(48)} \text {. }\end{array}$ & 1 & 2,5 \\
\hline Es el pegamento normativo que representa a toda la organización [Wagner, 2005; Brooks, 2006] ${ }^{(14) .}$. & 1 & 2,5 \\
\hline Como un sistema de orientaciones que mantienen las unidades organizacionales y les dan una identidad distinta & 1 & 2,5 \\
\hline
\end{tabular}


[Hoy y Miskel, 2010](33).

En un entorno hospitalario es el producto de valores, actitudes y patrones de comportamiento compartidos 1 [Stock, McFadden y Gowen, 2010](41).

Fenómeno social y un todo que consiste en ideas y pensamientos que mantienen a los empleados juntos [Schein, 1 $2010]^{(24)}$.

Emerge en la interacción social, se expresa en hábitos, estilos de trabajo y formas de relacionarse compartidos [Arciniega, 2011] ${ }^{(44)}$.

Es una estructura simbólica total, que es aprendida por los miembros del grupo, se convierte en una norma y los conduce [Livari y Livari, 2011] (49).

Es el pegamento social que sostiene una organización en conjunto [Tsai, 2011] ${ }^{(22) .}$

Consiste en las visiones compartidas, las ideologías, creencias, sentimientos, supuestos, expectativas, normas [Lunenburg y Ornstein, 2013] ${ }^{(34)}$.

Conjunto simbólico que da sentido a las acciones y orienta el comportamiento de las personas en la 1 organización [Serrate, Portuondo, Sánchez y Suárez, 2014](6).

Es el modo en que se comportan los individuos que participan en ella y los valores adquiridos por ellos, que 1 diferencian una de las otras [Sempionato, 2014](50).

Es un conjunto de actitudes y prácticas compartidas por los miembros de la organización y determinan su comportamiento [Engelen, Flatten, Thalmann y Brettel, 2014](20)

Involucra el patrimonio material, espiritual, herramientas, tradiciones y costumbres organizacionales [Belias, $1 \quad 2,5$ Velissariou, Kyriakou, Gkolia, Sdrolias, Koustelios, y Varsanis, 2016](46).

* Frecuencia de citación de definiciones de la subcategoría identidad organizacional

Tabla 4. Definiciones de acuerdo a la subcategoría Empresarial y aprendizaje organizacional

\begin{tabular}{|c|c|c|}
\hline Subcategoría Empresarial & Fi & $\%$ \\
\hline $\begin{array}{l}\text { Son las restricciones, oportunidades, normas, actitudes y comportamientos particulares que se crean en una } \\
\text { institución [Douglas, 1982](51). }\end{array}$ & 1 & 14,3 \\
\hline Es como una variable independiente e interna [Shrivastava, 1983] ${ }^{(52) .}$. & 1 & 14,3 \\
\hline $\begin{array}{l}\text { Incluye coherencia, orden y significado y permite la institucionalización de una estructura apropiada [Weick, } \\
\text { 1985](52). }\end{array}$ & 1 & 14,3 \\
\hline $\begin{array}{l}\text { La cultura corporativa se refiere a la manera de administrar una organización en el esfuerzo por mejorar la } \\
\text { eficacia y eficiencia de su desempeño general [Heskett 1992; Ooi y Arumugam, 2006; Ahiybor, } 2014 \text { y } \\
\text { Ghanavati 2014; Kotter] }]^{(30)} \text {. }\end{array}$ & 1 & 14,3 \\
\hline Es esencial para el éxito estratégico [Black, 2003](31). & 1 & 14,3 \\
\hline $\begin{array}{l}\text { Se moldea con las acciones de los líderes, asignando recursos, cómo reclutan, seleccionan y promueven } \\
\text { subordinados [Schein, 2004] }{ }^{(53) .}\end{array}$ & 1 & 14,3 \\
\hline $\begin{array}{l}\text { La cultura organizacional es la esencia misma de una firma de auditoría, sirviendo como un medio para } \\
\text { controlar el comportamiento indeseable de los empleados [Jenkins et al. 2008](53). }\end{array}$ & 1 & 14,3 \\
\hline
\end{tabular}



transmiten a los miembros de una sociedad en particular [Linton, 1945](13).

Es el patrón de premisas básicas que un determinado grupo inventó, descubrió o desarrolló en el proceso de aprender a resolver sus problemas de adaptación externa y de integración interna [Schein, 1985] ${ }^{(13,18,21,54)}$.

Son experiencias, significados, valores y entendimientos aprendidos, reproducidos y comunicados de forma simbólica [Alvesson, 1993] (55).

El conjunto de normas de conducta y actitudes de trabajo que rigen el comportamiento y promueven el éxito del entrenamiento [Baron y Kreps, 1999] ${ }^{(56) .}$

Es capaz de influenciar los pensamientos, sentimientos, interacciones y desempeño de los empleados en una organización [Saeed y Hassan, 2000](30).

Es un fenómeno socialmente aprendido y transferido a nivel grupal [Ashkanasy, Wilderom y Peterson, $2000]^{(57) .}$

Es aquella que influencia el pensamiento y las conductas de los empleados [Howard, 2007](30).

1

Es un facilitador del aprendizaje organizacional [Barette et al., 2012](52).

Está relacionada con la maestría personal, la visión compartida y el pensamiento sistémico [Mehrabi et al., 2012](52).

Interrelación de los procesos de apropiación de la filosofía, la pertenencia, la adaptación, la satisfacción y el liderazgo compartidos [Álvarez, et al, 2012](58).

Suposiciones básicas consideradas válidas y se enseñan a los nuevos miembros como una manera de percibir, pensar y sentir en la organización [Nelson y Quick, 2013] ${ }^{(59) .}$

Se observa como un patrón de supuestos compartidos y aprendidos por un grupo [Chidambaranathan y RaniKumaresan, 2015](39).

* Frecuencia de citación de definiciones de las subcategorías empresaria y aprendizaje organizacional

\section{Relación de cultura organizacional con otras variables}

La cultura organizacional se relaciona con 33 variables: $11,25 \%$ con desempeño y $11,25 \%$ con compromiso laboral, $10 \%$ con liderazgo, $10 \%$ con satisfacción laboral, 7,5\% con innovación, $5 \%$ con capacitación, $3,75 \%$ con trabajo, $3,75 \%$ con familia; gestión de conocimiento, ausentismo, valores de trabajo, trabajo en equipo y normas 2,5\%; felicidad, clima organizacional, análisis organizacional, gestión de personas, orientación estratégica, políticas salariales, asunción de riesgos, proactividad, calidad de servicio, disposición de cambio, seguridad, marketing, excelencia, gestión de calidad total, pensamiento crítico, ausentismo, contratación, recompensa, motivación y discapacidad 1,25\% (cada una).
En relación a la metodología empleada para estudiar la cultura organizacional el 43,7\%, (31) técnicas, 38\% (27) instrumentos y 18,3\% (13) tanto técnicas como instrumentos.

\section{Discusión}

La cultura organizacional se entiende como la codificación de valores, creencias, suposiciones, símbolos, lemas y ritos adquiridos y compartidos por los miembros de una organización, con los cuales se producen normas que configuran su comportamiento(13-20). La cultura es un tema de gran relevancia ya que le brinda al colaborador mayor salud y bienestar, al sentir que la organización reconoce sus competencias, conocimientos y habilidades, logrando la articulación con normas, políticas, procesos y procedimientos, permitiendo alcanzar un crecimiento personal y organizacional $(1,2)$. 
Se aprecia un aumento en un buen número de investigaciones sobre cultura organizacional durante los últimos seis años, donde se identifican los conceptos más utilizados en la actualidad; en el año 2014 es cuando más artículos relacionados con la temática se publicaron con un total de veinte y uno (21). La mayoría de estudios se realizaron en India, Estados Unidos de América, Brasil y Turquía, al respecto Aguilar ${ }^{(9)}$ refiere que la investigación de la cultura organizacional se ha desarrollado principalmente en países industrializados, esto se puede asociar a su desarrollo económico y a la creación de políticas referentes a la educación(60).

Existe un porcentaje alto de artículos publicados en inglés, evidenciando que este es el idioma prioritario de divulgación de los resultados de las investigaciones sobre cultura organizacional en diferentes países del mundo. En el análisis de las referencias, se puede observar que los autores más citados son: Cameron, Quinn, Spreitzer y Schein, quienes abordan la cultura organizacional desde diversas perspectivas que se enmarcan en la subcategoría de creencias y valores e identidad organizacional, esto puede explicarse puesto que las empresas en la actualidad buscan que los colaboradores movilicen sus recursos personales, para generar un vínculo con los principios gestores de la organización y guiar los esfuerzos hacia el cumplimiento de un objetivo en común.

La subcategoría de valores y creencias organizacionales se refiere a la motivación que permite cumplir al trabajador los objetivos esperados de la organización(61), de acuerdo a las creencias que son conceptos normativos creados en grupos culturales(62); En dicha subcategoría se encontró el mayor número de definiciones $38 \%(13,21)$, estas pueden ser entendidas desde dos perspectivas: la primera, como una construcción compartida por los miembros de una organización, la cual guía los comportamientos de los colaboradores(13,14,18-21,25,31,34); la segunda, vista desde la necesidad de una empresa de definir los estándares esperados de conducta de cada individuo, por lo cual dichos elementos son impuestos por la empresa y asumidos por el trabajador $(17,19,20)$.
La subcategoría actitud organizacional que hace referencia a la relación de los sentimientos, creencias y valores que se presentan en la organización, así como la predisposición de una persona para comportarse de una manera dada en el contexto laboral(63), presentó un 5\% de representatividad(16,32,46), indicando que la cultura organizacional se concibe en menor medida como sistemas cognitivos individuales, que al ser aceptados y seguidos por los colaboradores, se formalizan en la organización permitiendo facilitar la toma decisiones efectivas en el futuro(13,14,16,32,33).

La subcategoría identidad organizacional se refiere a todo aquello que permite distinguir a la organización como singular y diferente, lo cual posibilita tangibilizar las creencias, atributos y valores que son aprendidos por los colaboradores y reflejados en su trabajo(61). El $36 \%$ de los estudios se han interesado por las estructuras organizacionales que diferencian a la organización de las demás $(24,28,44,45,64)$. De igual manera, se encuentra que las concepciones de identidad organizacional se encausan en dos corrientes que si bien buscan dar identidad se enmarcan en dos contextos, uno en función de las estructuras o áreas que componen a la organización $(13,24,26,33,43,46) \quad y$ otra hacia los individuos que la conforman $(6,18,24,37,44,45,50)$.

La subcategoría empresarial define la cultura organizacional como la institucionalización de una estructura en la que se pretende mejorar la eficacia y eficiencia del desempeño en general, buscando que se reproduzcan normas, actitudes y comportamientos, para con ello controlar las conductas de los colaboradores(65). El 6\% de los estudios concibe la cultura organizacional como un medio para controlar el comportamiento de los empleados $(30,51,53,66)$. Es posible identificar que esta subcategoría concibe a la cultura organizacional como una estrategia para generar éxito empresarial(31)a partir de dos metodologías: la primera, con la administración del recurso humano en procesos de selección, remuneración y ascensos estratégicos $(30,52,53)$ y la segunda, por medio de la gestión de talento humano que potencia las competencias con las cuales ya cuentan los colaboradores ${ }^{(51)}$. 
La subcategoría Aprendizaje organizacional se refiere a la necesidad de los colaboradores de adquirir, crear, actualizar, compartir y/o renovar el conocimiento necesario para el desarrollo de sus actividades, este nuevo conocimiento puede ser adquirido por experiencias propias de su lugar de trabajo a partir de un aprendizaje activo(13,18-21,39,52,55,58) o transmitido por la organización a los nuevos integrantes como uno pasivo(13,22,56,57,59,67). Se identificó un $14 \%$ de estudios que comprenden la cultura organizacional como una forma de aprendizaje que permite resolver situaciones internas $y$ externas a la organización(18,54,48).

Se identificó la relación de la cultura organizacional con otras variables; es así que, $11,25 \%$ de publicaciones la relacionan con desempeño laboral(27,47,38), permitiendo comprender que la cultura manifestada en procedimientos, ritos, conductas, hábitos, entre $\operatorname{otras}^{(47)}$ y el desempeño laboral, constituyen la base de un buen funcionamiento organizacional, de tal manera que ambos factores sirven de referencia acerca de cómo las personas deben conducirse dentro de una organización o institución(68). El 11,25\% la relacionan con compromiso laboral $(18,30,42)$ como un mecanismo que guía y moldea las actitudes de los colaboradores(69), logrando con ello incrementar la estabilidad del sistema social de la organización. El $10 \%$ de publicaciones la correlacionan con liderazgo(15,55,70) haciendo referencia al proceso mediante el cual un individuo influye sobre la conducta de los demás con el fin de aportar significativamente a la construcción de la cultura organizacional(63). El $7,5 \%$ de las publicaciones la asocian con innovación (19,71,72), al existir dicho vínculo emerge una forma de pensar y actuar que genera, desarrolla y establece valores y actitudes en la empresa propensos a suscitar, asumir e impulsar ideas y cambios que supongan un capital tecnológico de mayor calidad y mejoras en el funcionamiento y eficiencia de la misma(73). El $5 \%$ la vinculan con capacitación $(35,56)$ como un medio asociado al sistema cultural que permite crear y reforzar la identificación que tiene el colaborador con la organización y así mismo propiciar la implementación de estrategias que favorezcan a la misma(74).

En la revisión de las definiciones de cultura organizacional fue posible identificar la forma de medir y evaluar dicho constructo a partir de la concepción que los autores tienen del mismo; así, se encontró tres tipos de metodologías: la primera, hace referencia a técnicas, entendidas como un conjunto de procedimientos que se llevan a cabo para recolectar información(75) encontrando principalmente la observación, entrevista y grupos focales; la segunda, es a través de un instrumento que representa la herramienta con la cual se recoge, registra, y codifica los datos, es decir que permite operacionalizar a la técnica(75) encontrando la escala de Cameron y Quinn; y la tercera, en la cual se encontró la utilización de técnicas e instrumentos conjuntamente; vislumbrando con ello que el estudio de cultura organizacional carece de un modelo único desde los enfoques que ofrece la psicología, ocasionando posiblemente que los objetivos, técnicas e instrumentos y procesos de análisis de información no se desarrollen de manera integral.

Se reconoce que medir el constructo de cultura organizacional, debe implicar más que la utilización de estrategias de medición, puesto que se debe tener presente un objetivo central de evaluación que en relación a un enfoque teórico, permita la implementación de herramientas cuantitativas y cualitativas hacia una descripción, clasificación, predicción e intervención del comportamiento organizacional, independientemente del país en que estén constituidas, su actividad económica o la trayectoria histórica(76,77).

\section{Conclusiones y recomendaciones}

Al encontrar y organizar en subcategorías las concepciones de cultura organizacional desde Tylor de 1971(13) hasta la más reciente de Dhingra y Punia de 2016(73) fue posible identificar el recorrido de la investigación de cultura organizacional, generando con ello aporte académico en el campo de la psicología 
del trabajo y las organizaciones; ya que, a partir del reconocimiento de las tendencias sobre las concepciones de cultura organizacional es posible fundamentar metodologías de evaluación e intervención sobre la misma.

Las definiciones se agruparon en subcategorías, cada una de las cuales refleja diversos puntos de vista que enmarcan la manera de entender la cultura organizacional.

Se evidencia la ausencia de un modelo único con el cual sea posible diagnosticar la cultura organizacional en las empresas, lo cual ha generado que dicho diagnóstico se dé mediante la utilización de un instrumento o técnica; se encuentran pocos estudios que reconocen la necesidad de un proceso integral de evaluación con el cual se obtendría mayor rigurosidad en el estudio de dicho constructo.

Se recomienda realizar una revisión sobre las investigaciones así como otras bases de datos; la profundización en las subcategorías antes descritas con el fin de evaluar las metodologías empleadas para su medición y de la misma manera proponer nuevas metodologías de investigación que se adapten a las necesidades actuales de las organizaciones. De igual trabajar el impacto de la gestión de la cultura en el cambio organizacional, la competitividad, el desarrollo humano y organizacional.

\section{Agradecimientos}

Al Programa de Psicología de la Universidad de Nariño y a la docente Edith Hernández por su invaluable acompañamiento y colaboración en la construcción del presente artículo, a la Unión Temporal Ciudad Sorpresa, por permitir la realización de la práctica profesional en su organización y al apoyo de todas las personas que contribuyeron en este proceso de formación como psicólogos.

\section{Conflicto de intereses}

Los autores declaran que no existen conflictos de intereses.

\section{Referencias}

1. Yeung A, Brockbank J, Ulrich D. Organizational Culture and Human Resources Practices: An Empirical Assessment. Research in Organizational Change and Development. 5th ed. Greenwich: JAI Press; 1991.

2. Calderón G, Murillo S, Torres K. Cultura organizacional y bienestar laboral. Cuadernos de Administración [Internet]. 2003 [citado 13 Mar 2018];16(25):109-137. Disponible en: http://revistas.javeriana.edu.co/index.php/cuadernos_ admon/article/view/5452/4214

3. Giordan A, De Vecchi G. Los orígenes del saber. Sevilla: Díada Editora; 1999.

4. Kiakajouri K, Jafar-nejad A, Hosein-zadeh A. The relationship between organizational culture and job satisfaction. Executive Management Research. 2010;10(2):87-108.

5. Gutiérrez E. Cultura, organizaciones e intervención. Univ Psychol [Internet]. 2006 [citado 13 Abr 2017];6(1):11-129. Disponible en:http://sparta.javeriana.edu.co/psicologia/publicaci ones/actualizarrevista/archivos/V6N110.pdf

6. Serrate A, Portuondo A, Sánchez N, Suárez R. Evaluación de la cultura organizacional y su incidencia en la efectividad grupal. Ingeniería Industrial [Internet]. 2014 [citado 18 Abr 2017];35(1):2-12. Disponible en:http://search.ebscohost.com/login.aspx?direct=true \&db=zbh\&AN=108922099\&lang=es\&site=ehost-live.

7. Ruiz Y, Naranjo J. La investigación sobre cultura organizacional en Colombia: una mirada desde la difusión en revistas científicas. Diversitas [Internet]. 2012 [citado 30 Abrl 2017];8(2):285-307. Disponible en:

http://www.redalyc.org/pdf/679/67925837006.pdf.

8. Salazar J, Guerrero J, Machado Y, Cañedo R. Clima y cultura organizacional: dos componentes esenciales en la productividad laboral. ACIMED [Internet]. 2017 [citado 18 Dic 2017];20(4):67-75. Disponible en:http://scielo.sld.cu/scielo.php?script=sci_arttext\&pi $\mathrm{d}=$ S1024-94352009001000004\&lng=es.

9. Aguilar A. El diagnóstico de la cultura organizacional o las culturas de la cultura. Global Media Journal [Internet]. 2009 [citado 4 Abr 2017];6(11):67-81. Disponible en: http://www.redalyc.org/pdf/687/68711445005.pdf

10. Fernández R. Introducción a la Evaluación psicológica. 1st ed. Madrid: Pirámide; 1996.

11. Velásquez J. Una Guía Corta para Escribir Revisiones Sistemáticas de Literatura Parte 1. DYNA. 2014;81(187):9-10.

12. Beltrán 0 . Revisiones sistemáticas de la literatura. Rev Colombiana de Gastroenterología [Internet]. 2005 [citado 8 Abr 2017];20(1):60-69. Disponible en: http://www.scielo.org.co/pdf/rcg/v20n1/v20n1a09.p df.

13. Izasa C. Transformación de la cultura organizacional: el caso de Rica Rondo y su integración con un grupo empresarial colombiano. Pensamiento y Gestión [Internet]. 2013 [citado 2 May 2017];(34):21-53. Disponible 
en:http://search.ebscohost.com/login.aspx?direct=true $\& d b=z b h \& A N=91100289 \&$ lang=es\&site $=$ ehost-live

14. Sabri P, Ilyas M, Amjad Z. Organizational Learning Culture and its Effects on Critical thinking skills on Female Teachers of Public Sector HEI. Bulletin Of Education \& Research [Internet]. 2015 [citado $20 \mathrm{Abr}$ 2017];37(2):1-23. Disponible en: http://search.ebscohost.com/login.aspx?direct=true\&d $\mathrm{b}=$ ehh\&AN=113573079\&lang=es\&site=ehost-live

15. Walker R, Aritz J. Women doing leadership: Leadership styles and organizational culture. International Journal of Business Communication [Internet]. 2015 [citado 16 Agos 2017];52(4):452-478. Disponible en: http://search.ebscohost.com/login.aspx?direct=true\&d b=buh\&AN=114259289\&lang=es\&site=ehost-live

16. Rai S, Lakshman C. Organizational culture and commitment among lay-off survivors: A tale of two MNCs in India. South Asian Journal of Management [Internet]. 2014 [citado 9 Jul 2017];21(4):7-26. Disponible

https://search.proquest.com/openview/8feb47caa407 51ab3069bc32c87fe974/1?pqorigsite $=$ gscholar $\& \mathrm{cbl}=46967$

17. Chow I. The roles of implementation and organizational culture in the HR-performance link. The International Journal of Human Resource Management [Internet]. 2012 [citado 1 Jun 2017];23(15):3114-3132. Disponible en: http://search.ebscohost.com/login.aspx?direct=true\&d $\mathrm{b}=\mathrm{buh} \& \mathrm{AN}=76446260 \&$ lang $=$ es \&site $=$ ehost-live

18. Dwivedi S, Kaushik S, Luxmi. Impact of Organizational Culture on Commitment of Employees: An Empirical Study of BPO Sector in India. Vikalpa [Internet]. 2014 [citado 23 Jun 2017];39(3):77-92. Disponible en: http://journals.sagepub.com/doi/pdf/10.1177/02560 90920140306

19. Brettel M, Chomik C, Flatten T. How Organizational Culture Influences Innovativeness, Proactiveness, and Risk-Taking: Fostering Entrepreneurial Orientation in SMEs. Journal of Small Business Management [Internet]. 2015 [citado 1 Sept 2017];53(4):868-885. Disponible

en:

http://search.ebscohost.com/login.aspx?direct=true\&d $\mathrm{b}=$ buh\&AN=109345749\&lang=es\&site=ehost-live

20. Engelen A, Flatten T, Thalmann J, Brettel M. The Effect of Organizational Culture on Entrepreneurial Orientation: A Comparison between Germany and Thailand. Journal of Small Business Management [Internet]. 2014 [citado 19 Abr 2017];52(4):732752.Disponible

en: http://search.ebscohost.com/login.aspx?direct=true\&d b=buh\&AN=102201150\&lang=es\&site=ehost-live

21. Landekić M, Šporčić M, Martinić I, Bakarić M. Influence of organizational culture on firm efficiency: competing values framework in Croatian forestry. Scandinavian Journal of Forest Research [Internet]. 2015 [citado 3 May 2017];30(7):624-636. Disponible en: http://search.ebscohost.com/login.aspx?direct=true\&d $\mathrm{b}=\mathrm{aph} \& \mathrm{AN}=108393354$ \&lang=es\&site=ehost-live

22. Körner M, Wirtz M, Bengel J, Göritz A. Relationship of organizational culture, teamwork and job satisfaction in interprofessional teams. BMC Health Services Research [Internet]. 2015 [citado 1 Jun 2017];15(1):1-12. Disponible en: http://search.ebscohost.com/login.aspx?direct=true\&d $\mathrm{b}=\mathrm{aph} \& \mathrm{AN}=108276555$ \&lang=es\&site=ehost-live

23. Morschle E, Costa V, dos Reis D, Silva E. A influência da cultura organizacional no processo de inovação: o caso da águia sistemas de armazenagem em ponta grossa, Paraná. Review of Administration and Innovation - RAI [Internet]. 2013 [citado en 7 May 2017];10(2):219-237. Disponible en: http://search.ebscohost.com/login.aspx?direct=true\&d $\mathrm{b}=\mathrm{buh} \& \mathrm{AN}=90498811$ \&lang=es\&site=ehost-live

24. Oz M, Kaya F, Cifci I. Evaluating the Organizational Culture Types of the 5-Star Hotel's in Istanbul in terms of the Cameron \& Quinn Competing Values Model. Journal of Yaşar University [Internet]. 2015 [citado 29 May 2017];10(40):6684-6691. Disponible en:http://dergipark.ulakbim.gov.tr/jyasar/article/view /5000113439/5000135952

25. Singh A, Gupta V, Dubey A, Singh A. The Role of WorkFamily Culture and Personality Traits in Organizational Citizenship Behavior (OCB) of First-Level Managerial Personnel. IUP Journal of Organizational Behavior [Internet]. 2017 [citado 7 May 2017];16(1):58-71. Disponible en: http://search.ebscohost.com/login.aspx?direct=true\&d $\mathrm{b}=\mathrm{buh} \& \mathrm{AN}=121362091$ \&lang=es\&site=ehost-live

26. Sok J, Blomme R, Tromp D. Positive and Negative Spillover from Work to Home: The Role of Organizational Culture and Supportive Arrangements. British Journal of Management [Internet]. 2014 [citado 1 Jun 2017];25(3):456-472. Disponible en: http://search.ebscohost.com/login.aspx?direct=true\&d b=buh\&AN=96967807\&lang=es\&site=ehost-live

27. De Melo Santos N, Bronzo M, Valadares M, Viela P. Cultura Organizacional, Estrutura Organizacional e Gestão de Pessoas como Bases para umaGestão Orientada por Processos e seus Impactos no Desempenho Organizacional. Brazilian Business Review [Internet]. 2014 [citado 24 Jul 2017];11(3):106-129. Disponible en: http://search.ebscohost.com/login.aspx?direct=true\&d

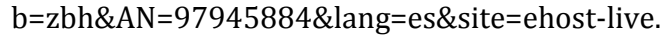

28. Wei Y, Samiee S, Lee R. The influence of organic organizational cultures, market responsiveness, and product strategy on firm performance in an emerging market. Journal of the Academy of Marketing Science [Internet]. 2013 [citado 17 May 2017];42(1):49-70. Disponible http://search.ebscohost.com/login.aspx?direct=true\&d $\mathrm{b}=\mathrm{buh} \& A N=93922469$ \&lang=es\&site=ehost-live

29. Ang M. Do Persons with Disabilities Act (2008) and Organizational Culture Influence Managerial Intention to Hire Persons with Disabilities?: The Malaysian Perspective. Jurnal Pengurusan [Internet]. 2014 [citado 27 May 2017];41:81-90. Disponible en: http://search.ebscohost.com/login.aspx?direct=true\&d b=buh\&AN=99747148\&lang=es\&site=ehost-live

30. Johari J, Nazir E. Elevating Organizational Commitment through Corporate Culture: A Case of Public Service 
Agencies in Malaysia. JurnalPengurusan [Internet]. 2015 [citado 10 Jun 2017];43:37-46. Disponible en: http://ejournal.ukm.my/pengurusan/article/view/111 $20 / 3679$

31. Dhingra R, Punia B. Impact of Organizational Culture on Employees' Readiness to Change. Journal of Management Research (09725814) [Internet]. 2016 [citado 11 May 2017];16(3):135-147. Disponible en: http://search.ebscohost.com/login.aspx?direct=true\&d $\mathrm{b}=\mathrm{buh} \& A N=120088655$ \&lang=es\&site $=$ ehost-live

32. Khan S. Influence of Organizational Culture on Teacher'sWorkEngagement: An Empirical Study. IUP Journal Of Organizational Behavior [Internet]. 2016 [citado 8 Jul 2017];15(4):27-45. Disponible en:http://search.ebscohost.com/login.aspx?direct=true \&db=buh\&AN=120476284\&lang=es\&site=ehost-live

33. Demir K. The Effect of Organizational Trust on the Culture of Teacher Leadership in Primary Schools. Educational Sciences: Theory \& Practice [Internet]. 2015 [citado 29 May 2017];15(3):621-634. Disponible en:

http://search.ebscohost.com/login.aspx?direct=true\&d $\mathrm{b}=\mathrm{aph} \& \mathrm{AN}=102840985 \&$ lang $=$ es\&site $=$ ehost-live

34. Özcan K, Karataș İ, Çağlar Ç, Polat M. Administrators' Power Usage Styles and Their Impact on the Organizational Culture in Colleges of Education: A Case Study. Educational Sciences: Theory \& Practice [Internet]. 2014 [citado 18 May 2017];14(2). Disponible en: http://search.ebscohost.com/login.aspx?direct=true\&d $\mathrm{b}=$ aph\&AN=96333144\&lang=es\&site=ehost-live

35. Simosi M. The moderating role of self-efficacy in the organizational culture-training transfer relationship. International Journal of Training and Development [Internet]. 2012 [citado 3 Sept 2017];16(2):92-106. Disponible

en: http://search.ebscohost.com/login.aspx?direct=true\&d $\mathrm{b}=\mathrm{buh} \& \mathrm{AN}=74713871$ \&lang $=\mathrm{es} \&$ site $=$ ehost-live

36. Al Murawwi M, Behery M, Papanastassiou M, Ajnial M. Examining the Relationship between Organizational Culture and Knowledge Management: The Moderation Effect of Organizational Divisions at an Abu Dhabi Gas Company. SAM Advanced Management Journal (07497075) [Internet]. 2014 [citado 28 May 2017];79(2):48-59. Disponible en: http://search.ebscohost.com/login.aspx?direct=true\&d $\mathrm{b}=\mathrm{buh} \& \mathrm{AN}=97568735 \&$ lang $=$ es\&site $=$ ehost-live

37. Mahalinga M, Suar D. Transformational Leadership, Organizational Culture, Organizational Effectiveness, and Programme Outcomes in Non-Governmental Organizations. Voluntas: International Journal of Voluntary and Nonprofit Organizations [Internet]. 2012 [citado 18 Mar 2017];23(3):684-710. Disponible en: http://search.ebscohost.com/login.aspx?direct=true\&d $\mathrm{b}=$ aph\&AN=77833924\&lang=es\&site=ehost-live

38. Acar A, Acar P. Organizational Culture Types and Their Effects on Organizational Performance in Turkish Hospitals. EMAJ: Emerging Markets Journal [Internet]. 2014 [citado 4 Agos 2017];3(3):18-31. Disponible en: http://search.ebscohost.com/login.aspx?direct=true\&d b=buh\&AN=95396273\&lang=es\&site=ehost-live
39. Marcio J, Oliveira C. The influence of organizational culture and strategic orientation in management of human resources: A case study. Revista de Administração da UNIMEP [Internet]. 2012 [citado 22 Agos 2017];10(1):1-28. Disponible en: http://search.ebscohost.com/login.aspx?direct=true\&d $\mathrm{b}=\mathrm{buh} \& \mathrm{AN}=78366428$ \&lang=es\&site=ehost-live

40. Alvarado O, Monroy del Castillo R. Cultura organizacional en una empresa propiedad de sus trabajadores. Cuadernos De Administración (01203592) [Internet]. 2013 [citado 4 May 2017];26(47):259-283. Disponible en: http://search.ebscohost.com/login.aspx?direct=true\&d $\mathrm{b}=\mathrm{zbh} \& A N=94075212$ \&lang=es\&site=ehost-live

41. Kobuse H, Morishima T, Tanaka M, Murakami G, Hirose M, Imanaka Y. Visualizing variations in organizational safety culture across an inter-hospital multifaceted workforce. Journal of Evaluation in Clinical Practice [Internet]. 2014 [citado 19 May 2017];20(3):273-280. Disponible en: http://search.ebscohost.com/login.aspx?direct=true\&d $\mathrm{b}=\mathrm{aph} \& A \mathrm{~N}=95908381$ \&lang=es\&site=ehost-live

42. Gokce B, Guney S, Katrinli A. Does Doctors' Perception of Hospital Leadership Style and Organizational Culture Influence Their Organizational Commitment. Social Behavior and Personality: an international journal [Internet]. 2014 [citado 10 Agos 2017];42(9):1549$1561 . \quad$ Disponible en: http://search.ebscohost.com/login.aspx?direct=true\&d $\mathrm{b}=$ aph\&AN=99055910\&lang=es\&site=ehost-live

43. Saillour F, Domecq S, Kret M, Sibe M, Dumond J, Michel $\mathrm{P}$, TheOReM group. Design and validation of a questionnaire to assess organizational culture in French hospital wards. BMC Health Services Research [Internet]. 2016 [citado 3 Jun 2017];16(1):1-15. Disponible en: http://search.ebscohost.com/login.aspx?direct=true\&d $\mathrm{b}=\mathrm{aph} \& \mathrm{AN}=118206863$ \&lang=es\&site=ehost-live

44. Arciniega R. Culturas organizacionales en empresas de la región Toluca-Lerma, Estado de México. Realidad mexicana [Internet]. 2013 [citado 1 May 2017];28(182):53-74. Disponible en: http://search.ebscohost.com/login.aspx?direct=true\&d $\mathrm{b}=\mathrm{zbh} \& A N=94752247$ \&lang=es\&site=ehost-live

45. Naranjo-Valencia J, Jiménez-Jiménez D, Sanz-Valle R. Studying the links between organizational culture, innovation, and performance in Spanish companies. Revista Latinoamericana de Psicología [Internet]. 2016 [citado 7 May 2017];48(1):30-41. Disponible en: http://doi:10.1016/j.rlp.2015.09.009.

46. Belias D, Velissariou E, Kyriakou D, Gkolia A, Sdrolias L, Koustelio A et al. The Advantages of Organizational Culture in Greek Banks. Journal Of Management Research [Internet]. 2016 [citado 19 Jul 2017];16(3):123-134. Disponible en: http://search.ebscohost.com/login.aspx?direct=true\&d $\mathrm{b}=\mathrm{buh} \& \mathrm{AN}=120088654$ \&lang=es\&site $=$ ehost-live

47. Revilla D, Santana R, Renteria M. La influencia de la cultura organizacional en el desempeño hospitalario. Revista De Sanidad Militar [Internet]. 2015 [citado 3 Agos 2017];69(5):429-439. Disponible en: 
http://search.ebscohost.com/login.aspx?direct=true\&d $\mathrm{b}=$ lth\&AN=110038287\&lang=es\&site=ehost-live

48. Latif $\mathrm{K}$, Ullah M. An Empirical Investigation into the relationship between Organizational Culture, Internal Service Quality [ISQ] and Organizational Performance. An Empirical Investigation into the relationship between Organizational Culture, Internal Service Quality [ISQ] and Organizational Performance [Internet]. 2016 [citado 10 Jun 2017];9(1):31-52. Disponible

en:http://search.ebscohost.com/login.aspx?direct=true $\& \mathrm{db}=$ aph \&AN=116805663\&lang=es\&site=ehost-live

49. Tanriverdi H, Çakmak C, Altindağ E. The Relationship of organizational culture and wage policies in turkish family firms. Business Management Dynamics [Internet]. 2016 [citado 14 May 2017];5(7):1-16. Disponible http://search.ebscohost.com/login.aspx?direct=true\&d b=buh\&AN=113776636\&lang=es\&site=ehost-live

50. Sempionato L. Cultura e clima organizacional: as causas do absenteísmo visto como efeito e não como causa do comportamento organizacional. Revista Brasileira de Administração Científica [Internet]. 2014 [cited 21 May 2017];5(1):82-95. Available from: http://search.ebscohost.com/login.aspx?direct=true\&d $\mathrm{b}=$ aph\&AN=114709585\&lang=es\&site=ehost-live

51. Weare C, Lichterman P, Esparza N. Collaboration and Culture: Organizational Culture and the Dynamics of Collaborative Policy Networks. Policy Studies Journal [Internet]. 2014 [citado 24 Jun 2017];42(4):590-619. Disponible en: http://search.ebscohost.com/login.aspx?direct=true\&d $\mathrm{b}=\mathrm{aph} \& A N=99543203 \&$ lang $=$ es\&site $=$ ehost-live

52. Pawluczuk A, Ryciuk U. Variables shaping the culture in organizational learning in municipalities. Contemporary Management Quarterly / Wspólczesne Zarzadzanie [Internet]. 2015 [citado 14 Jun 2017];14(2):51-62. Disponible en: http://search.ebscohost.com/login.aspx?direct=true\&d $\mathrm{b}=$ aph\&AN=111355768\&lang=es\&site=ehost-live

53. Baldacchino $\mathrm{P}$, Tabone $\mathrm{N}$, Agius J, Bezzina $\mathrm{F}$. Organizational Culture, Personnel Characteristics and Dysfunctional Audit Behavior. IUP Journal Of Accounting Research \& Audit Practices [Internet]. 2016 [citado 4 Jul 2017];15(3):34-63. Disponible en:http://search.ebscohost.com/login.aspx?direct=true $\& \mathrm{db}=\mathrm{buh} \& \mathrm{AN}=117347962 \&$ lang=es\&site $=$ ehost-live

54. Navaresse D, Yauch C, Goff K, Fonseca D. Assessing the Effects of Organizational Culture, Rewards, and Individual Creativity on Technical Workgroup Performance. Creativity Research Journal [Internet]. 2014 [citado 1 Jun 2017];26(4):439-455. Disponible en: http://doi:10.1080/10400419.2014.929428

55. Lescano L. Cómo fortalecer el clima y la cultura de servicio a través del liderazgo de servicio del mando intermedio: caso de estudio en una compañía multinacional. Revista Empresa y Humanismo [Internet]. 2017 [citado 18 Agos 2017];20(1):65-96. Disponible en: http://search.ebscohost.com/login.aspx?direct=true\&d $\mathrm{b}=\mathrm{zbh} \& A N=120814946 \&$ lang=es\&site=ehost-live
56. Ballesteros J, De Saá P, Domínguez C. The role of organizational culture and HRM on training success: evidence from the Canarian restaurant industry. The International Journal of Human Resource Management [Internet]. 2012 [citado 3 Sept 2017];23(15):32253242. Disponible en: http://search.ebscohost.com/login.aspx?direct=true\&d $\mathrm{b}=\mathrm{buh} \& \mathrm{AN}=76446256$ \&lang=es\&site=ehost-live

57. Blomme R, Sok J, Tromp D. The influence of organizational culture on negative work-home interference among highly educated employees in the hospitality industry. Journal of Quality Assurance In Hospitality \& Tourism [Internet]. 2013 [citado 13 Agos 2017];14(1):1-23. Disponible en: http://search.ebscohost.com/login.aspx?direct=true\&d $\mathrm{b}=$ fsr\&AN=85340733\&lang=es\&site=ehost-live

58. Nobel A, Velásquez J. Felicidad y desarrollo de la Cultura en las organizaciones: un enfoque psicosocial. Revista comunicación [Internet]. 2013 [citado 5 Jul 2017];12:7-31. Disponible en: http://search.ebscohost.com/login.aspx?direct=true\&d $\mathrm{b}=\mathrm{zbh} \& A N=92630498$ \&lang=es\&site=ehost-live

59. Guillaume 0, Austin A. Understanding organizational culture to transform a workplace behavior: Evidence from a liberal arts University. Scholedge International Journal of Management \& Development [Internet]. 2016 [citado 25 Jun 2017];3(4):89-96. Disponible en: http://search.ebscohost.com/login.aspx?direct=true\&d b=buh\&AN=117662160\&lang=es\&site=ehost-live

60. Neira I. Educación y Desarrollo Económico: El Papel de la Cooperación Internacional en el Desarrollo del Tercer Mundo. Euro-american association of economic development [Internet]. 2015 [citado 20 Sept 2017];47:1-17.

Disponibleen:http://www.eumed.net/cursecon/colabo raciones/aeeade47.pdf

61. Velásquez $\mathrm{Y}$, Rodríguez $\mathrm{C}$, Guaita W. Los valores Organizacionales: Referencia para la evaluación de la productividad [Internet]. Oa.upm.es. 2012 [citado 17 Agost 2017]. Available from:http://oa.upm.es/19402/1/INVE_MEM_2012_139 916.pdf

62. Pepitone A. El mundo de las creencias. Un análisis psicosocial. Rev Psicología Social y Personalidad [Internet]. 1991 [citado 8 Abr 2017];7(1):61-79. Disponible http://www.psicothema.com/pdf/553.pdf

63. Fuentes A. La Cultura Organizacional: Factor Clave del Éxito en las Empresas del Siglo XX [Administrador]. Universidad de Cartagena; 2012.Disponible en: http://190.242.62.234:8080/jspui/bitstream/11227/1 856/1/381-\%20ENSAYO\%20\%20LA\%20CULTURA\%20ORGANIZACIONAL\%20FACT OR\%20CLAVE\%20DE\%20\%C3\%89XITO\%20EN\%20L AS\%20EMPRESAS\%20DEL\%20SIGL0\%20XXI.pdf

64. Gimenez J, Jiménez D, Martínez M. Organizational culture for total quality management. Total Quality Management \& Business Excellence [Internet]. 2013 [citado 7 May 2017];24(5-6):678-692. Disponible en: http://search.ebscohost.com/login.aspx?direct=true\&d $\mathrm{b}=\mathrm{buh} \& \mathrm{AN}=87821049$ \&lang=es\&site=ehost-live 
65. Jenkins J,Deis D, Bedard J, Curtis M. Accounting Firm Culture and Governance: A Research Synthesis. Behavioral Research in Accounting [Internet]. 2008 [citado 30 Abr 2017];20(1):45-74. Disponible en:http://search.ebscohost.com/login.aspx?direct=true $\& d b=b u h \& A N=28716488 \&$ lang=es\&site=ehost-live

66. Sinha A, Arora B. Fit between Organizational Culture and Business Excellence: A Case Study of Heavy Electrical Equipment Plant, BHEL. Vikalpa [Internet]. 2012 [citado 26 Jun 2017];37(3):19-28. Disponible en: http://search.ebscohost.com/login.aspx?direct=true\&d $\mathrm{b}=\mathrm{buh} \& \mathrm{AN}=82330641$ \&lang=es\&site=ehost-live

67. Alcover C, Gil F. Crear conocimiento colectivamente: aprendizaje organizacional y grupal. RevPsicología del Trabajo y de las Organizaciones [Internet]. 2002 [citado 20 May 2017];18(2-3):259-301. Disponible en:http://www.redalyc.org/articulo.oa?id=231318274 008.

68. Figueroa L. Relación entre la cultura organizacional y el desempeño laboral de los colaboradores de una institución gubernamental [Licenciatura]. Universidad Rafael Landívar; 2015.Disponible en http://recursosbiblio.url.edu.gt/tesisjcem/2015/05/43 /Figueroa-Leyvi.pdf.

69. Bohorquez A. La cultura organizacional y su influencia en la gestión administrativa [Internet]. Biblioteca Digital. 2013 [citado 17 Sept 2017]. Disponible en: http://bibliotecadigital.usb.edu.co/bitstream/10819/2 225/1/Cultura_Organizacional_Administrativa_Bohorq uez_2013.pdf.

70. ElKordy M. Transformational Leadership and Organizational Culture as Predictors of Employees Attitudinal Outcomes. Business Management Dynamics [Internet]. 2013 [citado 18 Agos 2017];3(5):15-26. Disponible en:http://search.ebscohost.com/login.aspx?direct=true $\& \mathrm{db}=\mathrm{buh} \& \mathrm{AN}=110238169$ \&lang=es\&site=ehost-live

71. Peretz H, Levi A, Fried Y. Organizational diversity programs across cultures: effects on absenteeism, turnover, performance and innovation. The International Journal of Human Resource Management [Internet]. 2015 [citado 1 Sept 2017];26(6):875-903. Disponible en: http://web.b.ebscohost.com/ehost/pdfviewer/pdfview er?vid $=4 \&$ sid $=c 9071969-033 d-44 a 0-8235-$ 954522462d67\%40sessionmgr103

72. Eisend M, Evanschitzky H, Gilliland D. The Influence of Organizational and National Culture on New Product Performance. Journal of Product Innovation Management [Internet]. 2016 [citado 2 Sept 2017];33(3):260-276. Disponible en: http://search.ebscohost.com/login.aspx?direct=true\&d $\mathrm{b}=$ buh\&AN=114453042\&lang=es\&site=ehost-live

73. Bueno E, Morcillo P. Cultura e innovación: la conexión perfecta. Madrid [Internet]. 2003 [citado 20 Oct 2017];15. Disponible en: https://www.madrimasd.org/revista/revista15/tribun a/tribuna4.asp

74. Rodriguez R. La cultura organizacional un potencial activo estratégico desde la perspectiva de la administración. Invenio [Internet]. 2009 [citado 5 Sept
2017];12(22):67-92. Disponible en: http://www.redalyc.org/pdf/877/87722106.pdf

75. Peña K. Métodos, técnicas e instrumentos de investigación [Internet]. Academia.edu. 2013 [citado 21 Oct 2017]. Disponible en: http://www.academia.edu/6251321/M\%C3\%A9todos _t $\%$ C3\%A9cnicas_e_instrumentos_de_investigaci $\%$ C3\% B3n

76. Anastasi A, Urbina S. Test psicológicos. Bogotá: Pearson; 1998.

77. Fernández R. Introducción a la evaluación psicológica. Madrid: Ediciones pirámide; 1993. 